
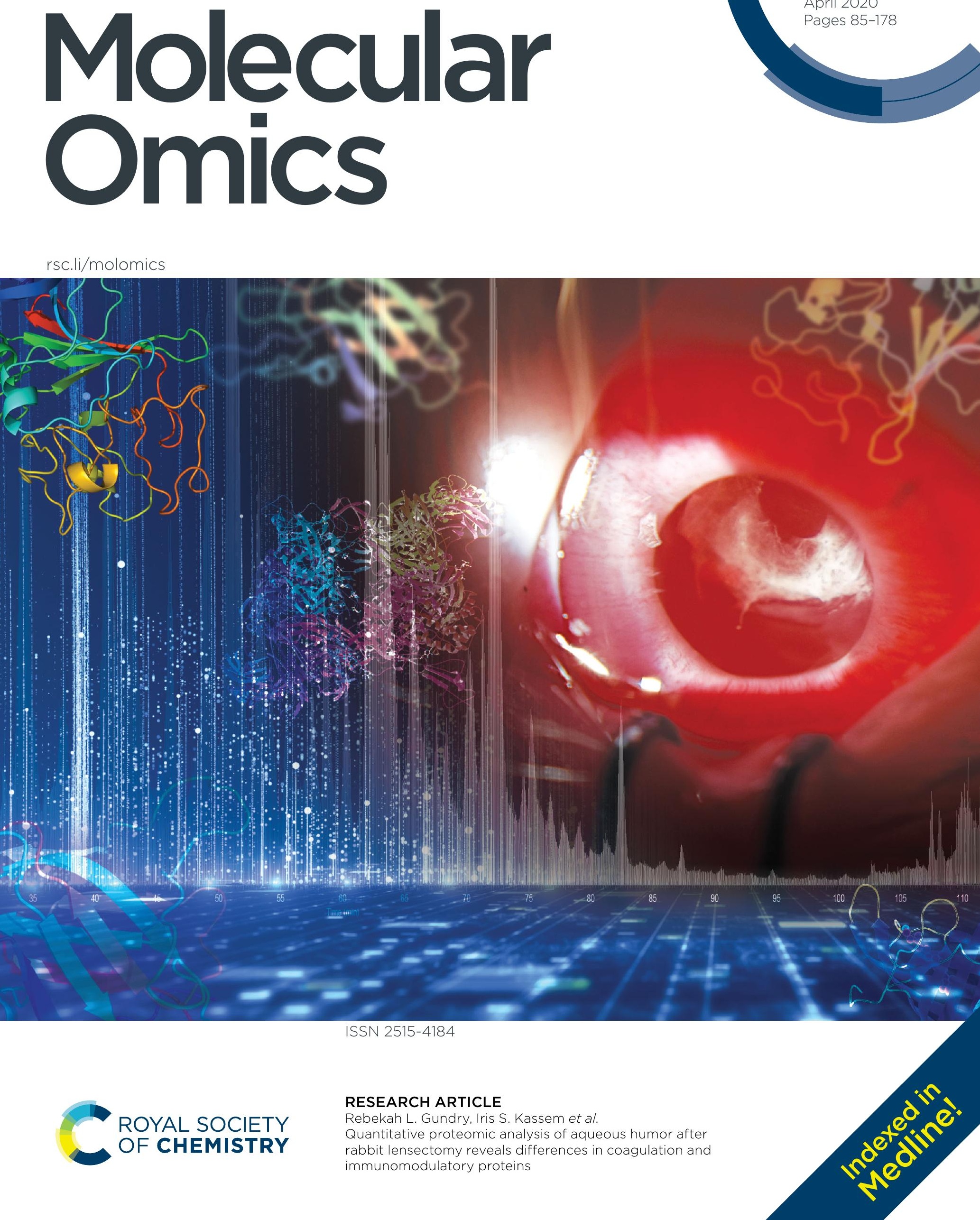
Check for updates

Cite this: Mol. Omics, 2020, 16,126

Received 21st November 2019, Accepted 20th January 2020

DOI: $10.1039 / \mathrm{c} 9 \mathrm{mo} 00169 \mathrm{~g}$

rsc.li/molomics

\title{
Quantitative proteomic analysis of aqueous humor after rabbit lensectomy reveals differences in coagulation and immunomodulatory proteins $\dagger$
}

\author{
Jonathon B. Young, (D) a Theodore R. Keppel, (D) ${ }^{b}$ Matthew Waas, \\ Alexander E. Salmon, (D) a Amanda Rae Buchberger, (D) ${ }^{b}$ Christine M.B. Skumatz, ${ }^{d}$ \\ Rebekah L. Gundry (D) *bee and Iris S. Kassem (D) *ad
}

\begin{abstract}
Compared to adults, children experience increased postoperative scarring and inflammation following intraocular surgery. While the underlying causes of the exaggerated immune response in children are not understood, proteins play key roles in postoperative scarring and wound healing processes. To identify and quantify proteins associated with the robust postoperative immune response, this study applied quantitative proteomics approaches to a juvenile rabbit model of lensectomy with intraocular lens (IOL) insertion. Twenty-six 6-7 week-old New Zealand white rabbits underwent unilateral portions of lensectomy with IOL insertion including: anterior chamber paracentesis, corneal incision with wound suture, lensectomy only, and lensectomy with IOL insertion. Aqueous humor was collected immediately prior and three days after each procedure. Semi-quantitative protein discovery was achieved by labelfree quantitation using data dependent and data independent acquisition modes. Based on the discovery results, targeted quantitation by parallel reaction monitoring of 3 proteins of interest, fibrinogen-beta chain, transforming growth factor beta-2, and retinol binding protein 3, was used to confirm the observed quantitative trends. Total protein concentration levels increased with each progressive surgical step of lensectomy with IOL insertion. Proteins related to the complement and coagulation cascades were found to increase in relative abundance, while proteins related to ocular immunosuppression decreased in abundance following surgery. These data provide insights into the postoperative response by providing the first surgical step-wise views of the $\mathrm{AH}$ proteome before and after surgery. Overall, this work provides the foundation for future investigations targeting specific proteins for therapeutic interventions aimed at minimizing postoperative complications after pediatric intraocular surgery.
\end{abstract}

\section{Introduction}

Juvenile cataracts are an opacification of the crystalline lens of the eye, estimated to cause 5 to $20 \%$ of blindness in children worldwide. ${ }^{1,2}$ Determining the optimal time to perform cataract extraction requires careful consideration as a lack of clear and focused vision in children can lead to potentially irreversible

\footnotetext{
${ }^{a}$ Cell Biology, Neurobiology, \& Anatomy, Medical College of Wisconsin, The Eye Institute, 925 N. 87th Street, Milwaukee, WI 53226, USA. E-mail: ikassem@mcw.edu; Tel: +1 414-955-7803

${ }^{b}$ Center for Biomedical Mass Spectrometry Research, Medical College of Wisconsin, Milwaukee, WI, USA

${ }^{c}$ Biochemistry, Medical College of Wisconsin, Milwaukee, WI, USA

${ }^{d}$ Ophthalmology \& Visual Sciences, Medical College of Wisconsin, USA

${ }^{e}$ CardiOmics Program, Center for Heart and Vascular Research, Division of Cardiovascular Medicine and Department of Cellular and Integrative Physiology, University of Nebraska Medical Center, Omaha, NE 68198, USA.

E-mail: rebekah.gundry@unmc.edu; Tel: +1 402-559-4426

$\dagger$ Electronic supplementary information (ESI) available. See DOI: 10.1039/c9mo00169g
}

vision loss due to amblyopia. ${ }^{3}$ Pediatric cataract surgery has a greater risk for complications than adult surgery due to the enhanced postoperative response in children, ${ }^{4}$ resulting in surgeons pursuing one of two treatment options. One option is to leave the patient aphakic, where the cataract is removed without primary intraocular lens (IOL) implantation and the resulting refractive error is treated with glasses or contact lenses. However, contact lenses for aphakia remain costly and are a considerable burden to caregivers. Contact lens-related adverse events including corneal abrasion, ulcer, or keratitis occur in approximately $18 \%$ of aphakic patients. ${ }^{5}$ Another surgical option is to insert an IOL at the same time as lensectomy, offering continuous refractive correction. However, due to the exaggerated immune response associated with IOL insertion, postoperative scarring can result in complications that can also limit the child's vision. ${ }^{6}$

The underlying cause of the exaggerated response to intraocular surgery in children remains unknown. A juvenile rabbit 
animal model of lensectomy has been shown to have a similar response to surgery and is therefore informative for the study of mechanisms that result in robust inflammation and fibrin formation. ${ }^{7}$ In addition, juvenile rabbits exhibit similarities in anterior chamber size and lens diameter, ${ }^{8}$ rendering them an ideal animal model for pediatric anterior segment studies utilizing similar techniques and materials to those used in human surgery. Rabbits provide a cost-effective, controlled environment for proteomic and surgical investigations. Although variations in each animal may exist, the genetic similarity between animals and the response to surgery is quite uniform in the rabbit population. Furthermore, rabbits provide opportunities to sample the aqueous humor before and after a surgical intervention. While human samples are typically collected prior to elective surgery, post-operative aqueous samples are only available in cases where another surgery or reoperation is required, thus usually limiting the aqueous sample to pre-surgical conditions. Hence, the rabbit surgery model provides controlled conditions to determine which proteins may play key roles in the exaggerated immune response before and after surgery.

Mass spectrometry (MS) approaches have previously been used to identify rabbit aqueous humor $(\mathrm{AH})$ proteins, including changes in response to different incisions. ${ }^{9,10}$ One study identified 98 proteins from four general functional groups including wound healing, protease inhibitors, antioxidant protection, and inflammatory proteins. ${ }^{9}$ In a second study, perturbations in the $\mathrm{AH}$ proteome following different corneal incision methods were compared without major changes observed for wound healing or anti-inflammatory proteins following the various corneal incisions. ${ }^{10}$ Altogether, these previous studies of the AH proteome have focused on surgical incisions but have not included conditions of lensectomy or IOL insertion. Consequently, it is not yet clear which portion of the pediatric cataract removal procedure causes postoperative fibrin formation.

In the current study, MS was used to quantify $\mathrm{AH}$ proteome changes in juvenile rabbits subjected to lensectomy with IOL insertion, using a surgical step-wise approach, to identify and quantify proteins responsible for the exaggerated immune response and fibrin formation observed in previous work. ${ }^{7}$ This work is the first to combine quantitative proteomics in a juvenile rabbit model following lensectomy with IOL insertion. Combining proteomics with this juvenile animal model provides an opportunity to examine how the ocular immune system responds to a corneal incision versus removal of the lens, thus offering significant insights into which proteins may cause postoperative scarring and inflammation at these specific surgical steps. Consequently, determining how the protein profile changes at each surgical step can help deduce the cause of the inflammatory and fibrotic response observed following surgery. In this work, relative quantitation of the AH proteome was performed for each progressive stage of the lensectomy with IOL insertion procedure, including a clear corneal incision, lensectomy alone, and lensectomy with IOL insertion. By defining the $\mathrm{AH}$ basal proteome and postoperative changes with progressive surgical steps using MS-based quantitation, this work lays the foundation for identifying the mechanisms responsible for exaggerated postoperative scarring in children. This work also reveals candidates for future investigations aimed at identifying therapeutic targets to improve postoperative visual outcomes by preventing or mitigating postoperative complications for visually significant cataracts.

\section{Experimental}

\section{Experimental design}

All experiments were approved and in compliance with the Institutional Animal Care and Use Committee at the Medical College of Wisconsin. Six to seven-week old, 600-900 g, New Zealand white rabbits from Kuiper Rabbit Farm (Gary, IN) were housed in a 14 hour light, 10-hour dark cycle and fed a diet of pelleted chow (Laboratory Rabbit Diet High Fiber 5326, LabDiet ${ }^{\circledR}$, St. Louis, MO) daily and a Timothy hay cube twice per week (Bioserv ${ }^{\circledR}$, Flemington, NJ). Rabbits were anesthetized with isoflurane (5\% induction, $2.5-4 \%$ maintenance) with 2 liters per minute of oxygen for surgery and postoperative exams. Eyes were topically anesthetized with $0.5 \%$ tetracaine hydrochloride (Bausch \& Lomb Inc., Tampa, FL) and dilated with $1 \%$ tropicamide and $2.5 \%$ phenylephrine (Akorn, Inc., Lake Forest, IL) before each procedure. The eye was prepared with povidone iodide solution (Medline Industries, Mundelein, IL) and draped in sterile ophthalmic fashion. Preoperative $\mathrm{AH}$ samples (Pre) were collected via corneal paracentesis with a 27 gauge needle on a $1 \mathrm{~mL}$ tuberculin syringe. Using the same technique, $\mathrm{AH}$ samples were collected again on post-operative day 3 (POD3). AH samples were collected, placed on ice, and divided into $25 \mu \mathrm{L}$ aliquots. Samples were then frozen at $-80{ }^{\circ} \mathrm{C}$ until further analysis.

Rabbits were divided into surgical groups including paracentesis $(n=9)$, incision with suture $(n=6)$, lensectomy $(n=6)$, and lensectomy with IOL ( $n=5$; Fig. $1 \mathrm{~A})$. For the paracentesis (control) group, samples were collected Pre and POD3 without any additional surgical intervention. Additional rabbits for the paracentesis group were used due to the needle contacting the lens described in detail below. For the incision with suture group, the anterior chamber (AC) was reformed with viscoelastic (sodium hyaluronate, $20 \mathrm{mg} \mathrm{mL}^{-1}$; Keralon ${ }^{\mathrm{TM}} \mathrm{V}++$, Keragenix, Rapid City, SD) after AH sampling. A clear-corneal incision was made just anterior to the limbus using a 20 gauge MVR blade, the viscoelastic was removed with balanced salt solution on a canula, and the wound was then closed with buried 10-0 nylon suture. For the lensectomy group, the same procedure was performed as in the incision with suture group, but following the corneal incision, a cystotome needle was used to puncture the anterior capsule followed by a continuous curvilinear capsulorhexis. The lens was then removed by irrigation and aspiration via a Simcoe double lumen irrigation/aspiration cannula. Following lens removal, a buried 10-0 nylon suture was used to close the wound. For lensectomy with IOL, the same procedures were performed as in the lensectomy group, with the anterior chamber filled with viscoelastic after lens removal. A $2.4 \mathrm{~mm}$ keratome was then used to expand the original incision. An acrylic foldable intraocular 
A
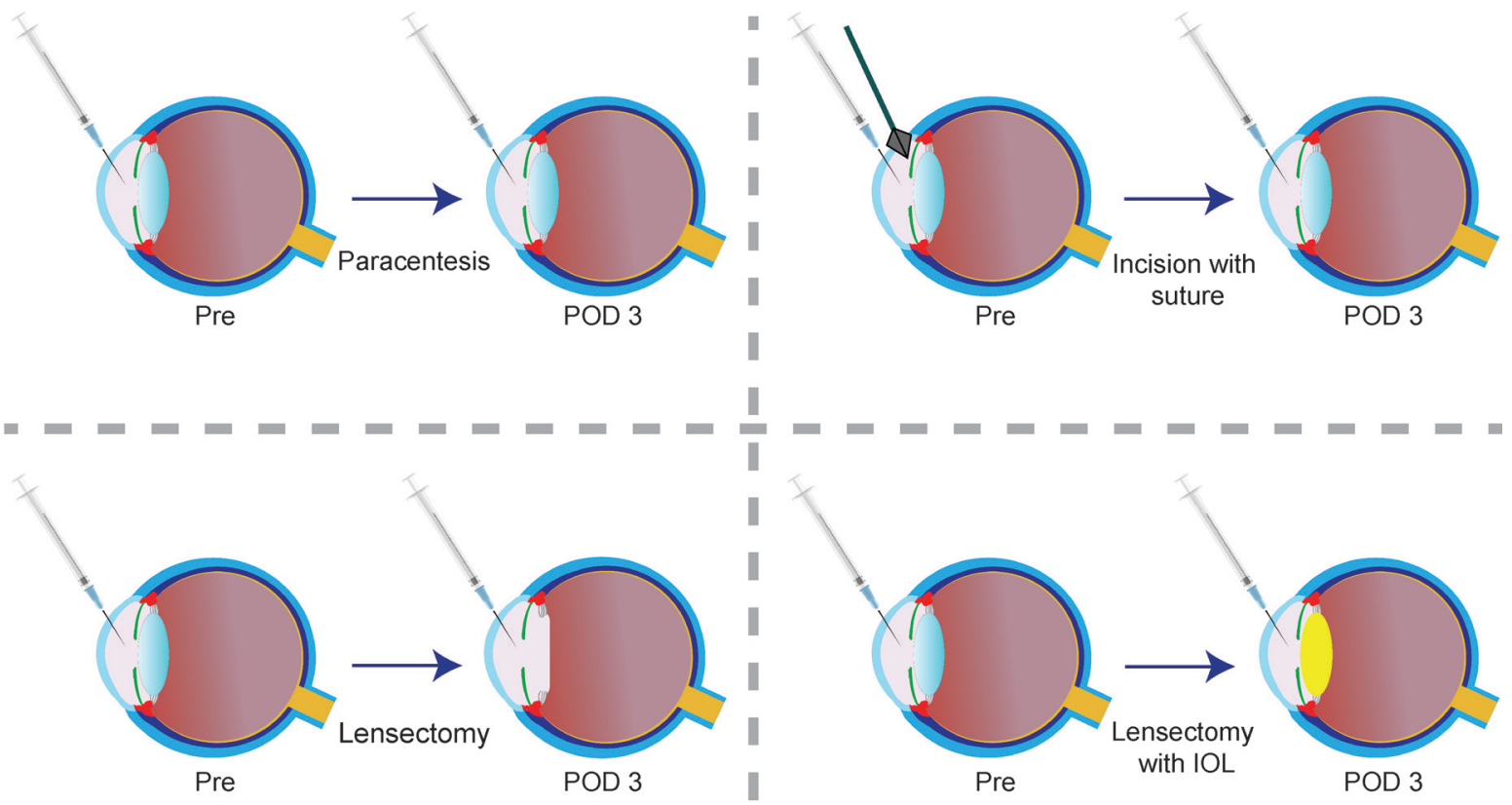

POD 3

B

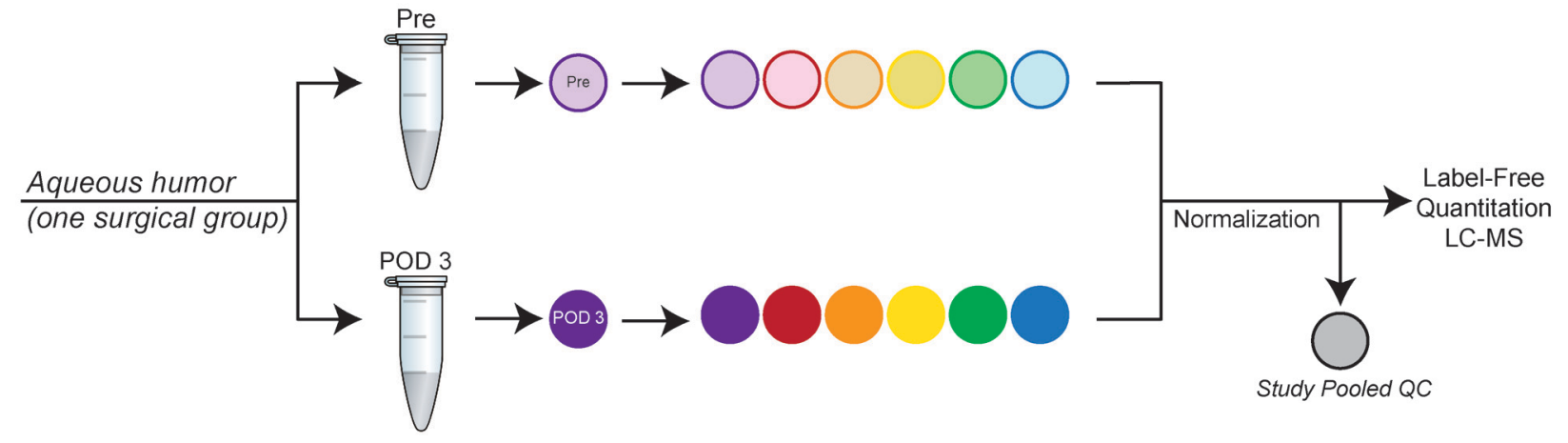

$C$

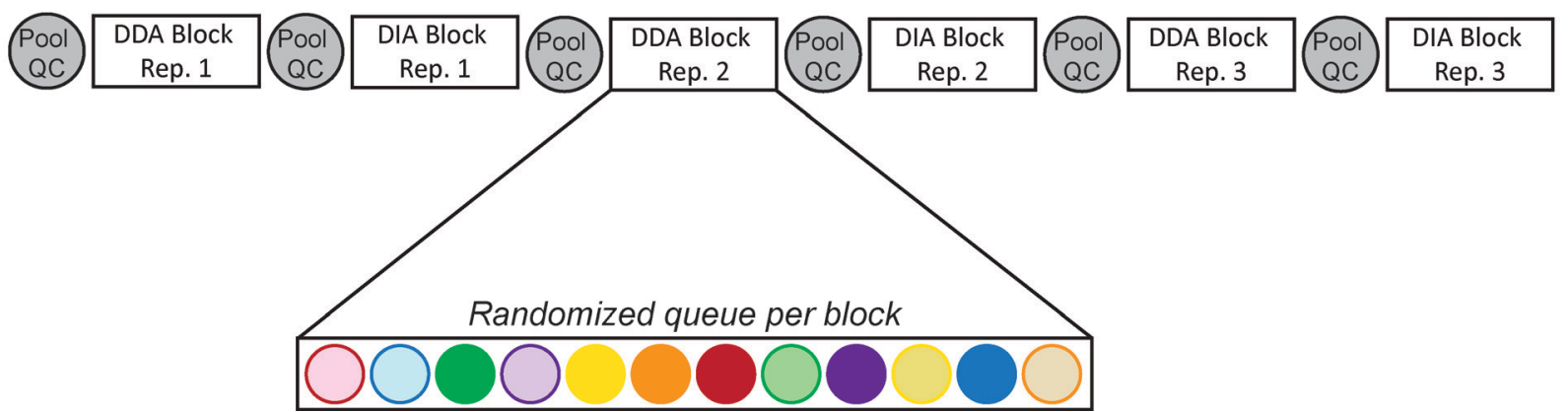

Fig. 1 AH sample collection \& discovery proteomics workflow. (A) Pre and POD3 samples were collected based on "steps" of surgical intervention. (B) Pre and POD3 AH samples from individual rabbits were normalized to the lowest measured peptide quantity within a surgical group, and aliquots from each sample were also merged to generate a study pooled QC sample. (C) Overview of the label-free quantitative analysis sample queue for each surgical step.

lens (SN60WF 30D lens, Alcon, Fort Worth, TX), was inserted into the capsular bag. Viscoelastic was then removed with
Simcoe irrigation and aspiration and the wound closed with a buried 10-0 nylon suture. After all the procedures, topical 
erythromycin ointment was applied twice daily for 3 days and analgesia was provided with subcutaneous buprenorphine (0.01-0.05 $\left.\mathrm{mg} \mathrm{kg} \mathrm{kg}^{-1}\right)$ at the time of surgery and then perioperatively twice a day for 3 days as needed.

\section{Postoperative clinical examinations}

Postoperatively, rabbits were examined under sedation with isoflurane on POD3. Slit lamp biomicroscopy (Topcon SL-D8Z; Topcon Medical Systems, Oakland, CA) was performed with photographs obtained using a Nikon D810 camera (Nikon, Melville, NY) to evaluate each eye.

To examine the correlation between the severity of fibrin scarring with each surgical step, the percent of the pupil covered by scarring was recorded by seven masked observers, including a board-certified ophthalmologist. Slit-lamp photographs were randomized, and the observers were asked to estimate the approximate percent fibrin coverage using a $0-100 \%$ scale in increments of $0-25 \%, 26-50 \%, 51-75 \%$, or 76-100\%.

For each image, the average score was calculated from all the observers.

\section{Total protein concentration assessment}

Protein concentration was determined using a BCA protein assay (bicinchoninic acid; Pierce Biotechnology, Rockford, IL) with bovine serum albumin as the standard. The microplate procedure was followed according to the manufacturer's instructions. All AH samples were diluted with PBS in a range of $1: 4-1: 10$ dilution in order to fall within the dynamic range of the assay.

\section{Quantitative discovery of aqueous humor proteins}

$10 \mu \mathrm{L}$ of each $\mathrm{AH}$ sample was diluted with $90 \mu \mathrm{L}$ of $100 \mathrm{mM}$ ammonium bicarbonate with $0.1 \%$ anionic acid labile surfactant I (AALS-I, Protea Biosciences, Morgantown, WV). The samples were brought to $5 \mathrm{mM}$ tris(2-carboxyethyl)phosphine (TCEP) and reduced with mixing, then brought to $10 \mathrm{mM}$ iodoacetamide and alkylated with mixing in the dark. Trypsin (Promega, Madison, WI), was added in a 1:20 trypsin-toprotein ratio, and the samples were digested overnight with mixing at $37{ }^{\circ} \mathrm{C}$. AALS-I was cleaved by adding $5 \mu \mathrm{L}$ of $10 \%$ trifluoroacetic acid and mixing for 10 minutes at $1400 \mathrm{rpm}$ using a Thermomixer (Eppendorf, Hamburg, Germany). Samples were desalted using reversed-phase elution from SOLA $\mu$ HRP 96-well plates (Thermo Fisher Scientific, Waltham, MA) according to the manufacturer's protocol, lyophilized, and stored frozen at $-80{ }^{\circ} \mathrm{C}$ until use.

Samples were re-dissolved in $20 \mu \mathrm{L}$ of $2 \%$ acetonitrile, $0.1 \%$ formic acid, and $\sim 98 \%$ LC-MS water. The peptides were quantified using a Pierce ${ }^{\mathrm{TM}}$ Quantitative Fluorometric Peptide Assay (Thermo Fisher Scientific), and the samples were normalized to the lowest measured peptide quantity across the samples within their respective surgical group. Peptide Retention Time Calibration (PRTC) Mixture (Thermo Fisher Scientific) was added to each sample at a final concentration of $2 \mathrm{nM}$ to enable retention time calibration and assessment of instrument performance throughout acquisition. Equal volumes of each sample were combined into a single "pooled QC" mixture.

The experimental design is outlined in Fig. 1B and C. Data were acquired using both data dependent acquisition (DDA) and data independent acquisition (DIA) strategies. ${ }^{11}$ Only DIA data were acquired for pooled QC samples, with injections inserted at the start of the surgery stage sample block, between each technical injection series of DDA and DIA, and at the end of the sample block ( 7 injections in total per surgery stage block). Samples were queued in a randomized order within a technical injection series, with 3 technical replicates each for both DDA and DIA modes (6 runs in total per sample). Peptides were analyzed by LC-MS/MS using a Dionex UltiMate 3000 RSLCnano system in-line with an Orbitrap Fusion ${ }^{\mathrm{TM}}$ Lumos $^{\mathrm{TM}}$ Tribrid $^{\mathrm{TM}}$ mass spectrometer (Thermo Fisher Scientific). All chromatography and instrumentation settings can be found in ESI, $\dagger$ Tables S1 and S2. All RAW files and other relevant data files are publicly available at MassIVE (MSV000084150; massive.ucsd.edu), with descriptions of all RAW files (Rabbit ID, technical replicate, surgical intervention, Pre/POD3) provided in ESI, $\dagger$ Table S9.

All data analysis details are provided in ESI, $\dagger$ Table S4. Briefly, MS data were processed using Proteome Discoverer 2.2 (Thermo Fisher Scientific) using Sequest HT to search against the UniProt rabbit database (accessed October 10, 2017; 23044 entries) with Percolator validation. Contaminants from the MaxQuant Contaminants Database (created October 13, 2017; 245 entries) were excluded from downstream analyses. The precursor mass tolerance was $10 \mathrm{ppm}$ with a fragment mass tolerance of $0.02 \mathrm{Da}$. The carbamidomethyl fixed modification was allowed, along with the dynamic modifications of oxidation (M) and acetylation (protein N-terminus). Protein identifications were filtered to include only those proteins identified by two or more unique peptides with target false discovery rates of $<1 \%$. Only proteins identified in greater than $50 \%$ of the biological replicates for each group in the discovery cohort were further considered. For these proteins, gene ontology analyses were performed using DAVID. ${ }^{12}$

Matched-spectrum files from the DDA analysis were imported into Skyline ${ }^{13}$ (v.4.1.0) to generate a spectral library for DIA analysis. The DIA data were used to confirm quantitative trends only for the set of proteins selected for further analysis. Briefly, DIA raw fragment peak areas were extracted, summed, and averaged across the 3 technical injections (ESI, $\dagger$ Table S8). Comparative ratios and statistical significance were then calculated using the MSstats plugin for Skyline. Assessing the DIA data provided additional confidence regarding the quantitative trends for proteins identified via DDA (Table 2), especially for proteins not detected by DDA within a particular surgical group.

\section{Targeted quantitation of proteins of interest}

To enable quantitative comparisons across surgical groups and establish further confidence in the quantitative trends observed in the discovery dataset, targeted quantitation by parallel reaction monitoring (PRM) was performed for three proteins 
of interest: fibrinogen-beta chain (FGB), transforming growth factor beta-2 (TGF- $\beta 2$ ), and retinol binding protein 3 (RBP3). Targeted analyses were consistent with the guidelines for Tier 2 analysis as described by Carr and colleagues. ${ }^{14}$ For each protein, three stable isotopically labeled (SIL) peptides were obtained (>95\% purity; New England Peptide Inc., Gardner, MA). Additional peptide information can be found in ESI, $\dagger$ Table S5.

SIL peptides were added to 34 samples representing a subset of the discovery cohort. Twelve paired samples (Pre and POD3) were selected from the paracentesis and lensectomy groups, and 10 paired samples were selected from the lensectomy with IOL groups. All samples were normalized to the same peptide concentration to allow direct comparisons across all groups. For each SIL peptide, $20 \mathrm{fmol}$ were added to $20 \mathrm{ng}$ of the previously digested and desalted peptides, and the samples were queued in a blocked and randomized order with a pooled QC similar to that of the discovery analyses in an unblinded fashion (chromatography and MS instrument acquisition settings provided in ESI, $\uparrow$ Table S3). Peptides were filtered within Skyline to include only: [+2] precursor charge, [+1] product ion charge, y-ion types, and product ion 3 to the last ion. A calibration curve was generated using an external dilution series with pooled QC samples, consisting of 7 concentrations with a range of 0.2 to $100 \mathrm{fmol}$, run before and after the sample block (two technical replicates). Raw total product ion peak areas for endogenous and SIL peptides were extracted using Skyline (v.4.2.1). The stability of each SIL peptide signal was assessed by determining the coefficient of variation (CV) of the total product ion peak area from each rabbit sample. Only peptides with CVs less than $15 \%$ were included in the final analysis. From one technical injection, approximate endogenous peptide concentrations for each sample were calculated by reference to the calibration curve following a log-scale transformation (Supplementary file S6, ESI $\dagger$ ). The peptide concentrations of each protein were averaged to estimate protein concentration.

\section{Statistical analysis}

Total protein concentration data, total protein concentration versus fibrin percentage, and SIL peptide results were analyzed using GraphPad Prism 8.0.2 (GraphPad, La Jolla, CA). Using GraphPad software, one-way analysis of variance (ANOVA) followed by post-hoc Tukey's test was used for total protein concentration data and SIL peptide analyses. A paired $t$-test was performed within Proteome Discoverer 2.2 to determine statistical significance for differences in individual protein abundances before and after surgery (POD3/Pre) within the same rabbit. The MSstats plugin for Skyline was used for the DIA analyses. $^{15}$

\section{Results \& discussion}

\section{Clinical correlation of $\mathrm{AH}$ total protein concentration}

The total amount of inflammation and fibrin formation increased at each surgical step (Fig. 2). In the paracentesis (control) group, no scarring was observed within the pupil. The cornea, conjunctiva, and iris all appeared healthy and had no visible signs of clinical pathology in 7 of 9 rabbits (Fig. 2A). During paracentesis on 2 of the 9 rabbits, the paracentesis needle came into contact with the lens capsule during sample collection, resulting in a minor fibrin scar. For the incision with suture eyes, a scar was observed near the site of incision, but all other ocular structures were within normal limits (Fig. 2B). However, in the eyes with lensectomy, fibrin formation within the pupil (Fig. 2C) was observed, although not obscuring the entire pupil. In the lensectomy with IOL group, the majority of the pupil was obscured by fibrin. Following lens insertion, iris scarring also prevented the pupil from complete dilation (Fig. 2D).

The average total protein concentration (Fig. 2E) for the Pre and POD3 samples significantly increased with each progressive intervention from $3.6 \mathrm{mg} \mathrm{mL}^{-1}$ and $3.4 \mathrm{mg} \mathrm{mL} \mathrm{m}^{-1}$ in the paracentesis and incision with suture groups, respectively, to $7.2 \mathrm{mg} \mathrm{mL}^{-1}$ following lens removal, and to $12.1 \mathrm{mg} \mathrm{mL}^{-1}$ in the lensectomy with IOL group. The total protein concentration was strongly correlated (Pearson's correlation of 0.85 ) with the percent fibrin coverage of the pupil as assessed by masked observers (Fig. 2F).

\section{AH proteomic analysis}

Reproducibility across triplicate samples for each surgical step was assessed using a principal component analysis (PCA) (Fig. 3). For DDA analysis alone, the paracentesis (Fig. 3A), incision with suture (Fig. 3B), lensectomy (Fig. 3C), and lensectomy with IOL (Fig. 3D) had highly reproducible replicates as shown on the PCA plot, providing high confidence in the quality of the data for each technical replicate.

At each surgical intervention, the number of proteins identified ranged from 286 to 362 (Table 1). The total number and identities of all proteins and peptides detected in each surgical step are provided in Table 2 and ESI, $\uparrow$ Table S7, respectively. Quantitative changes were observed with each surgical step as compared to pre-surgery, with the greatest fold changes occurring following IOL insertion (Fig. 4). As expected, trends from DDA and DIA were largely consistent and protein groups that were highly enriched from the DAVID analysis included those associated with the complement cascade and blood coagulation categories, and protein abundance ratios from both DDA and DIA acquisition modes for these proteins are reported in Table 2.

The abundance of fibrinogen-beta chain (FGB) significantly increases following lensectomy, corresponding to the clinical outcomes observed (Fig. 2C and D). Interestingly, RBP3 and TGF- $\beta 2$ were either observed to decrease in abundance or were not detected in postoperative samples (Table 2). DIA data were further inspected to determine whether the lack of detection was due to a true absence of detectable signal compared to difference in the stochastic sampling of the DDA method and in the case of TGF- $\beta 2$ confirmed that the peptides are detected, but at considerably lower intensity in POD3 compared to pre-surgery (ESI, $\dagger$ Fig. S1).

To obtain additional confidence regarding the observed changes in abundance, targeted quantitation was performed 

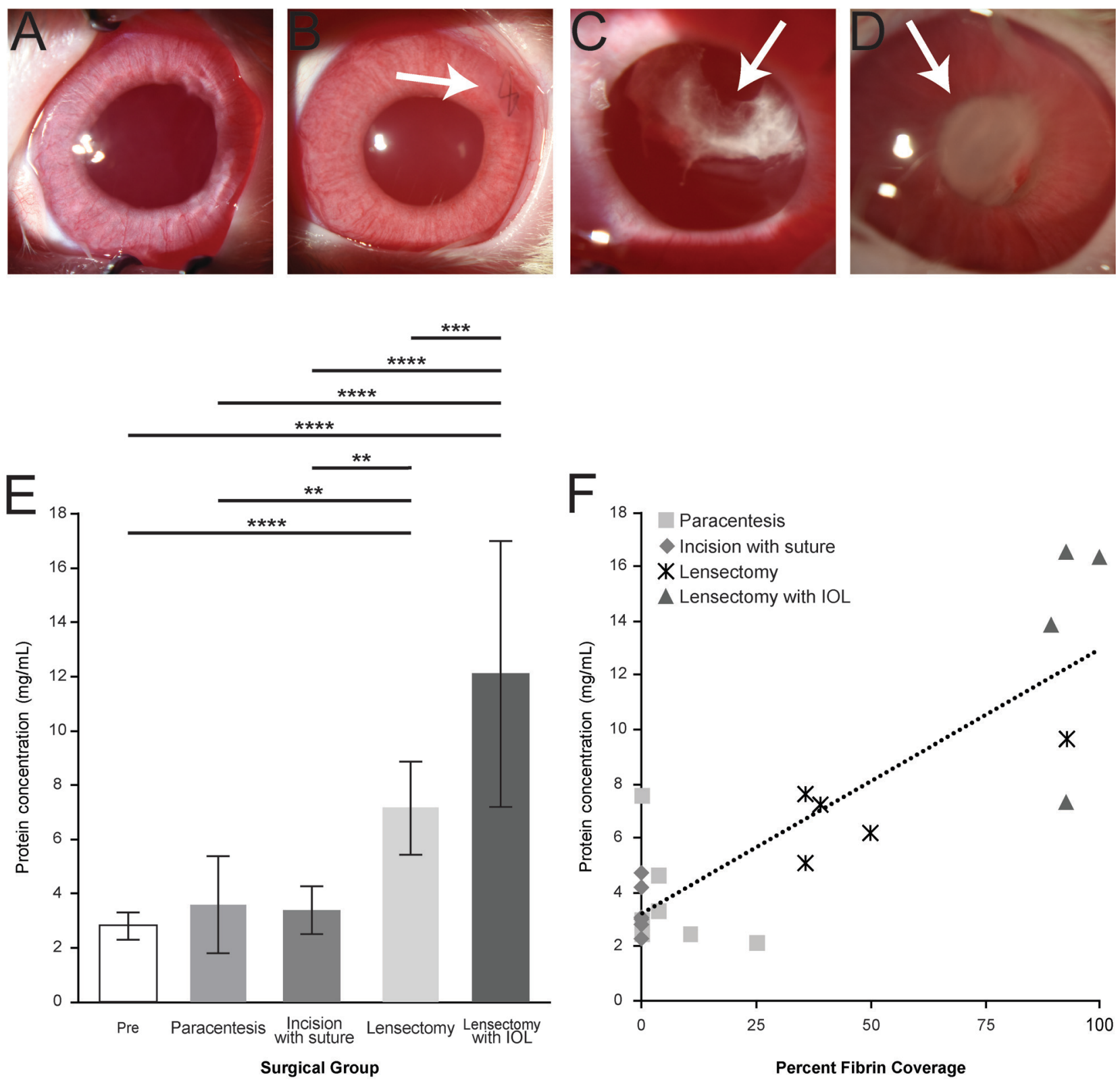

Fig. 2 Slit-lamp biomicroscopy POD3 of each surgical step. Representative slit-lamp photographs of (A) paracentesis, no evident scarring observed; (B) incision with suture, scar located adjacent to suture placement (arrow); (C) lensectomy, minor fibrin formation observed (arrow); (D) lensectomy with IOL insertion, major fibrin formation observed (arrow), significantly occluding the visual axis. (E) Total protein concentration determined by BCA assay. The amount of total protein at each surgical intervention, values shown as mean \pm SD. (F) Correlation of protein concentration ( $\mathrm{mg} \mathrm{mL}^{-1}$ ) versus percent of fibrin coverage.

using PRM with SIL peptide internal standards. Of the three peptides selected for each protein of interest, two peptides for TGF- $\beta 2$ and FGB and one peptide for RBP3 were deemed stable (SIL peptides with $\mathrm{CV}<15 \%$ ) and were used for quantitative analyses (Table S5 and Supplementary file S6, ESI + ). Overall, the quantitative trends in protein abundance following lensectomy were consistent between the discovery and targeted quantitation analyses (Fig. 5). For FGB, there was an increase in abundance in this protein, especially following the lensectomy surgical step (Fig. 5A). For TGF- $\beta 2$ (Fig. 5B) and RBP3 (Fig. 5C), a significant decrease in abundance of these proteins following lensectomy was confirmed.
The underlying causes of the exaggerated postoperative response observed following pediatric ocular surgery remain unclear. This study utilized a surgical step-wise approach to investigate which steps in the surgery cause enhanced inflammation and fibrin formation, including a comparison of corneal incision alone versus lens removal. To determine the proteins responsible for this response, $\mathrm{AH}$ samples were analyzed with high resolution, high accuracy MS for discovery and subsequent targeted quantitation. It is expected that defining the protein profile changes at each surgical step will inform which aspects of the procedure initiate the inflammatory and 


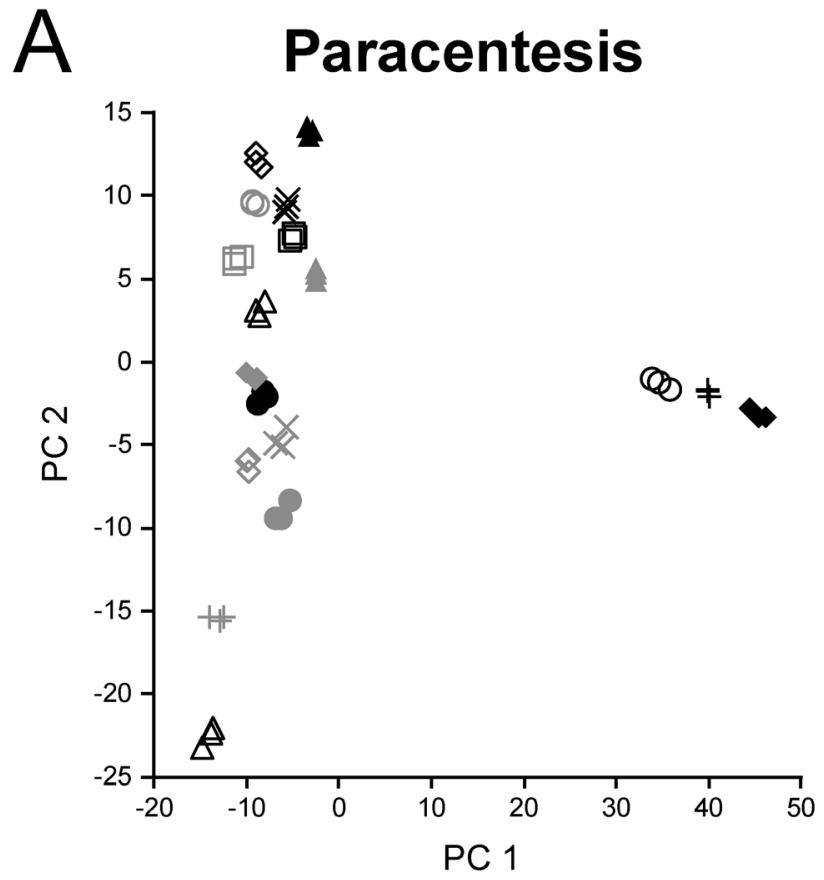

B Incision with suture
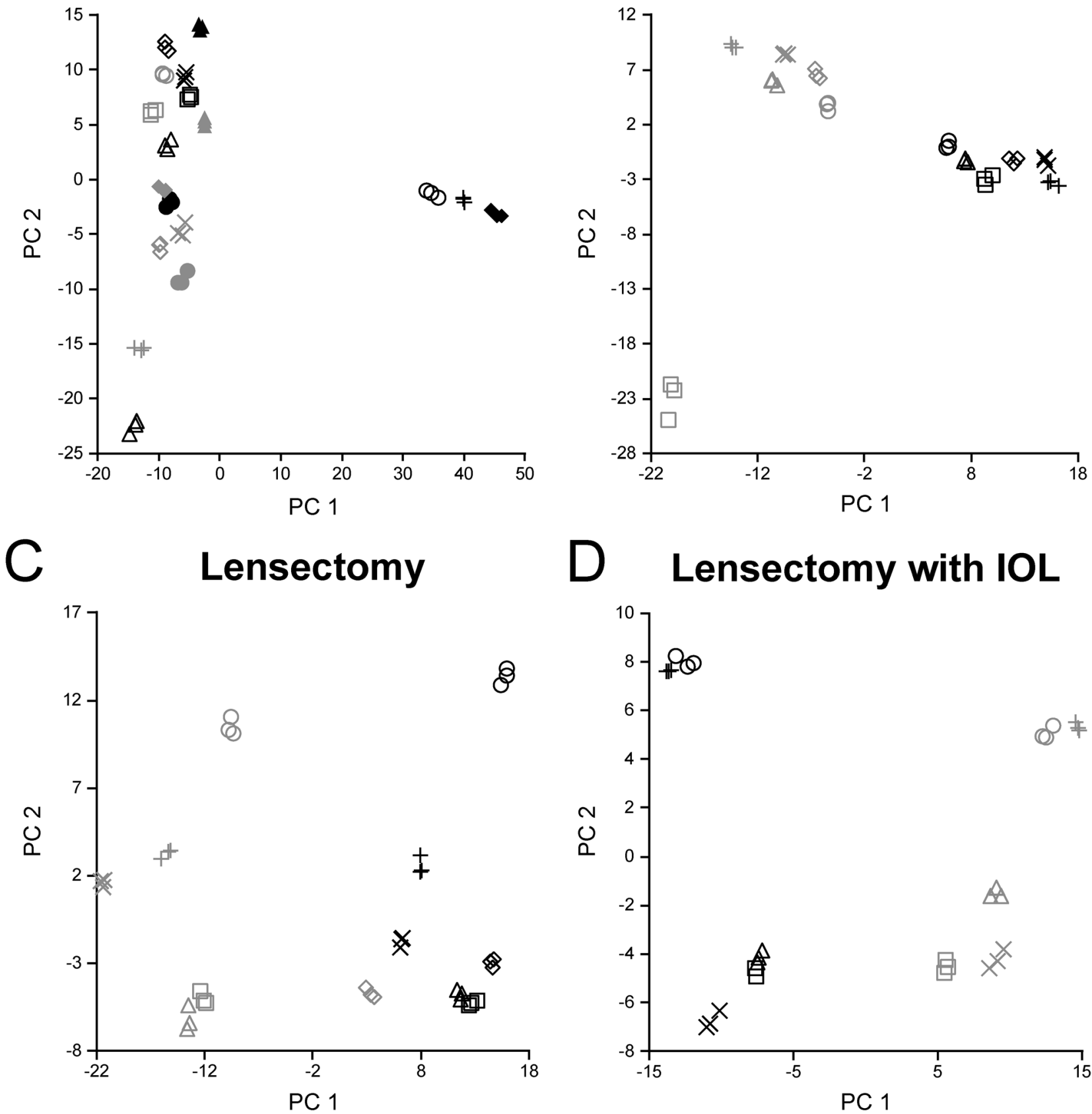

D Lensectomy with IOL

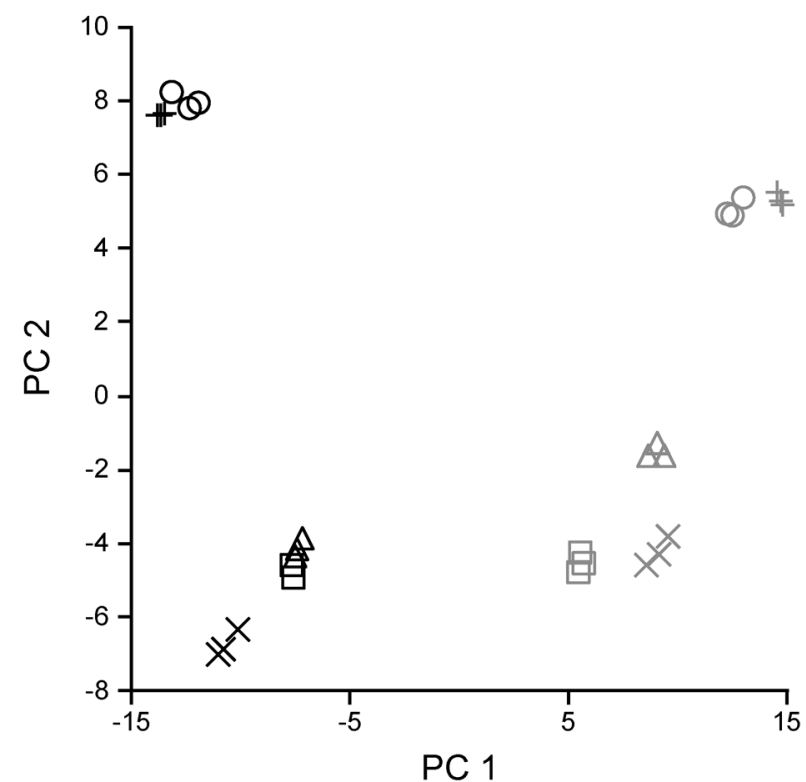

Fig. 3 PCA plots for each surgical step during DDA acquisition. Pre-surgical samples are illustrated in light grey and POD3 samples in black, with one rabbit corresponding to each symbol. Each set of technical replicates clustered together, indicating similarity between each technical replicate.

Table 1 The numbers of proteins that were identified in greater than $50 \%$ of the biological replicates for each surgical group. All of the proteins found in each group can be found in ESI, Table S7

\begin{tabular}{lllll}
\hline & \multicolumn{3}{l}{ Number of proteins identified } & \\
\cline { 2 - 5 } Group & Paracentesis & $\begin{array}{l}\text { Incision } \\
\text { with suture }\end{array}$ & Lensectomy & $\begin{array}{l}\text { Lensectomy } \\
\text { with IOL }\end{array}$ \\
\hline Pre & 356 & 299 & 321 & 324 \\
POD3 & 362 & 286 & 299 & 303
\end{tabular}

fibrotic cascades and those that mediate fibrin scarring. The investigation of different surgical steps, along with proteomic analysis following lensectomy with IOL insertion in a controlled environment with $\mathrm{AH}$ sample collection before and after surgical intervention using the juvenile rabbit model, have not been previously described and provide data for investigations not routinely possible with human subjects.

Clinical examination with slit lamp biomicroscopy revealed a positive correlation between anterior chamber fibrin formation 


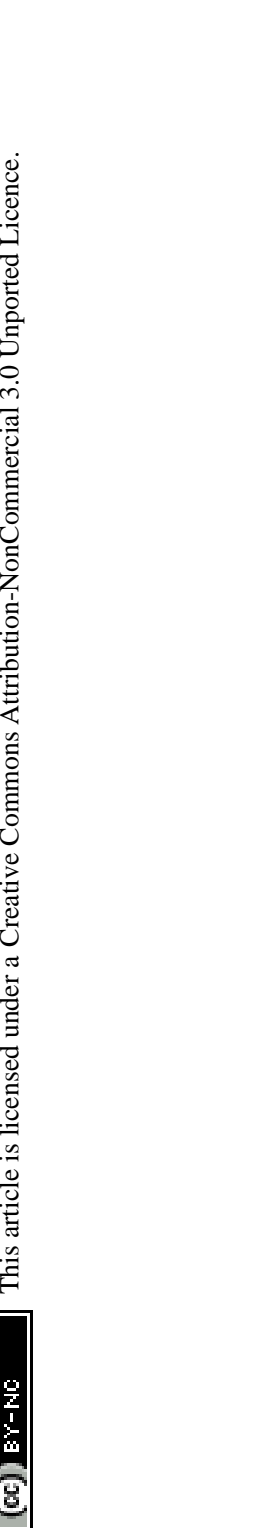

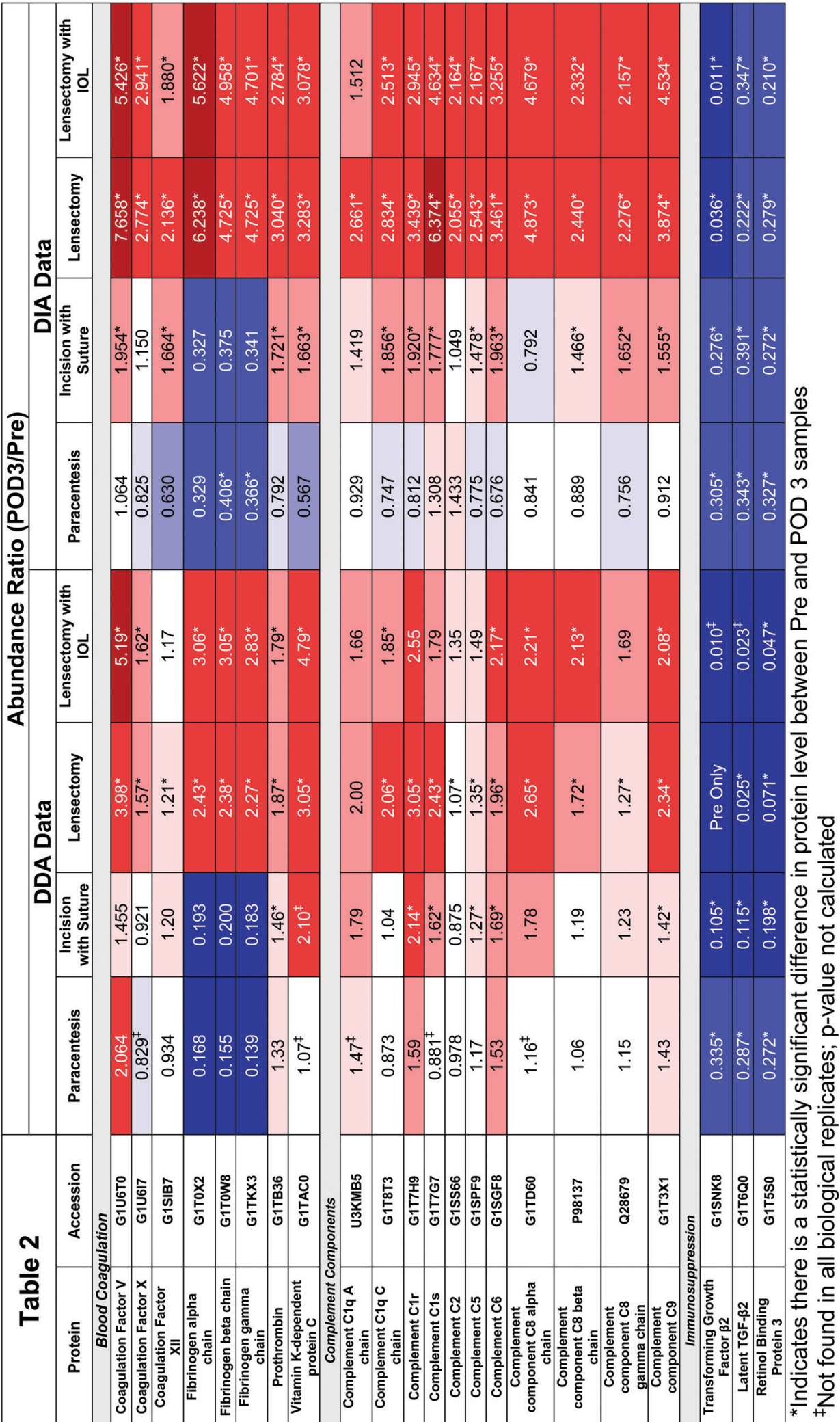



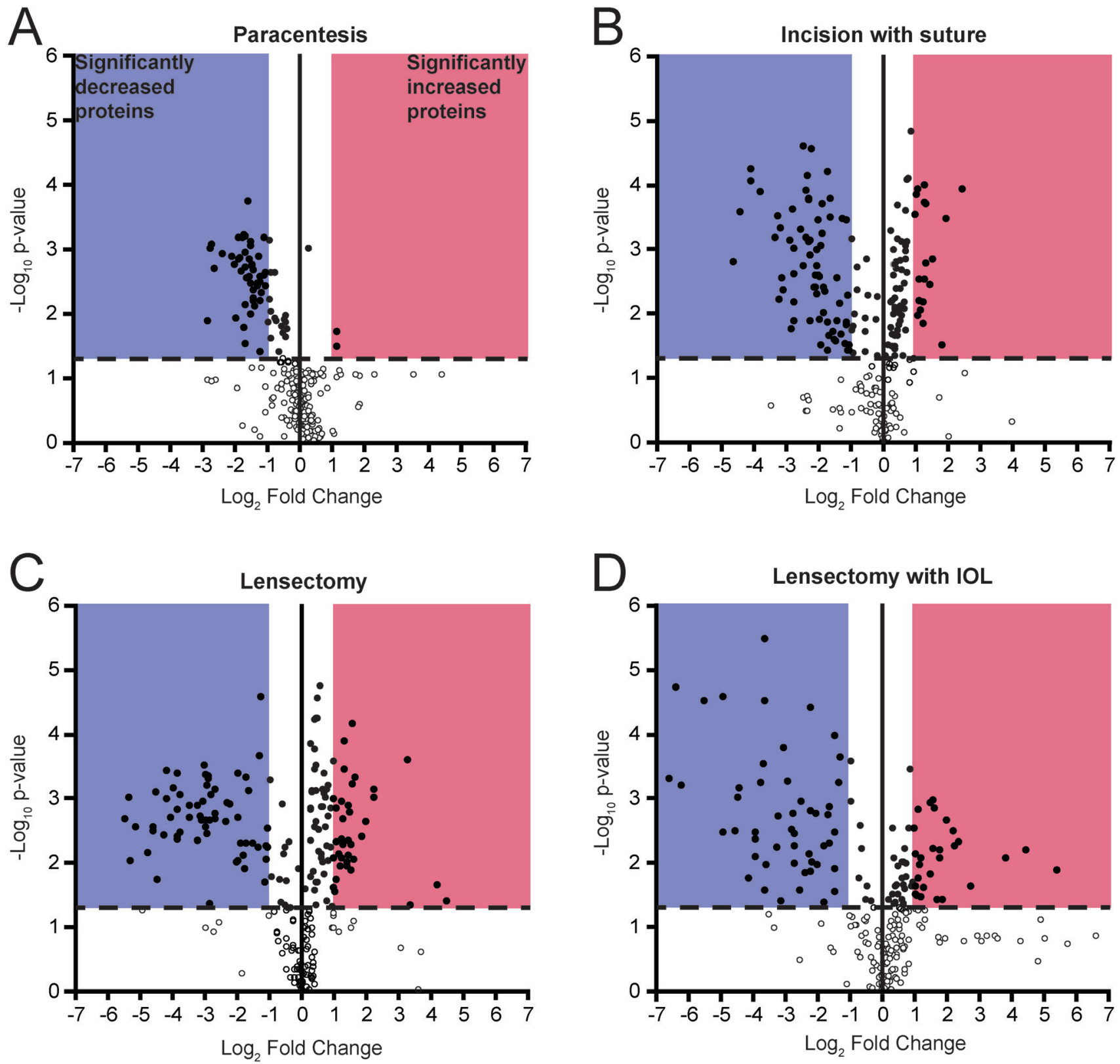

Fig. 4 Volcano plots for each surgical step from DDA data. Dashed line indicates significance threshold of $p<0.05$ using paired $t$-test. Dots represent proteins identified in all biological replicates.

and $\mathrm{AH}$ total protein concentration, progressing with each surgical step (Fig. 2). Despite a progressive increase in the overall protein concentration, the volcano plots reveal that select proteins decrease in abundance at each surgical step compared to the preoperative samples (Fig. 4). Other proteins, such as those related to the complement and coagulation cascades, increased in abundance, especially following lensectomy (Fig. 4 and Table 2). Differences were also observed in the relative abundance ratios of the fibrinogen alpha, beta, and gamma chains, which comprise the fibrin scar. ${ }^{16}$ In the lensectomy and lensectomy with IOL insertion steps, the fibrinogen chains are significantly increased in abundance, consistent with the observation that both groups had a larger area of fibrin scar (Fig. 2). Only a few coagulation factors and complement factors significantly increased following a corneal incision (Table 2), with clinical results revealing a minor fibrin scar near the incision site (Fig. 2). While previous studies have previously found these proteins in the cornea, ${ }^{17,18}$ this study suggests that these proteins do not drastically increase in abundance in the aqueous humor following a corneal incision. Notably, once a lensectomy is performed, all complement factors and coagulation factors reported in Table 2 significantly increase in abundance, suggesting that agitation of the lens rather than a corneal incision alone initiates the vast postoperative immune response observed.

Targeted quantitation of FGB, a key component of the fibrin matrix, ${ }^{16}$ confirmed the trends observed in the semi-quantitative 
Fibrinogen beta chain

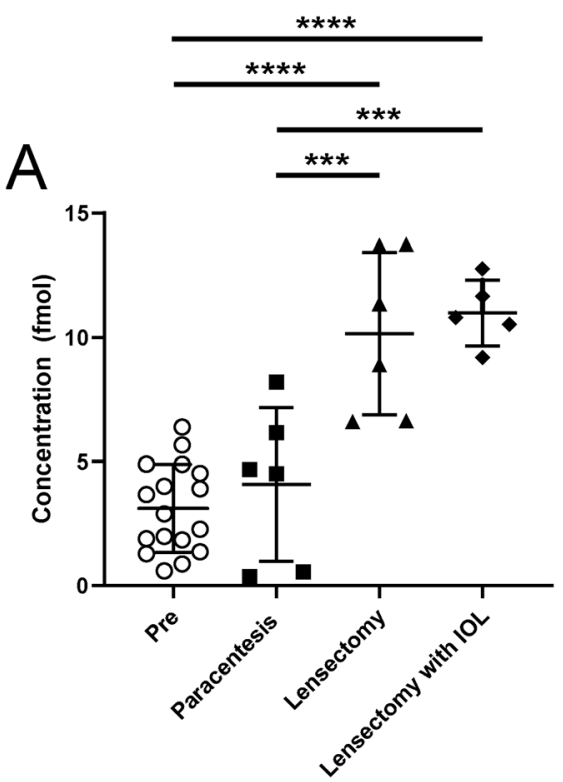

Transforming growth factor $\beta 2$

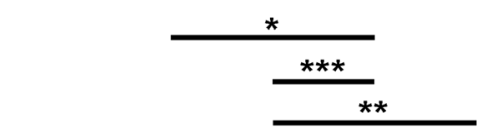

B

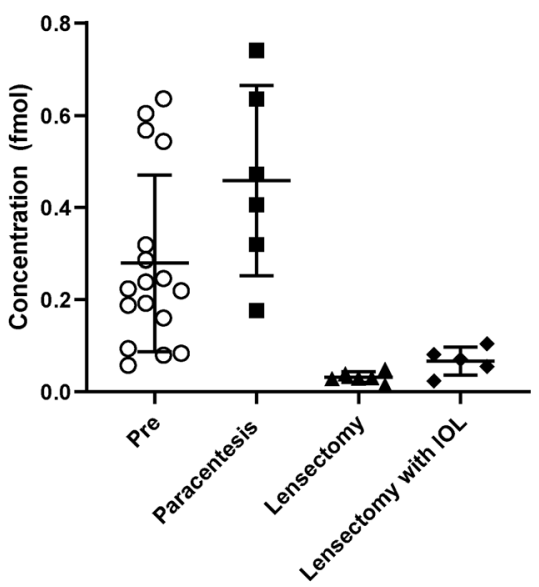

Retinol binding protein 3

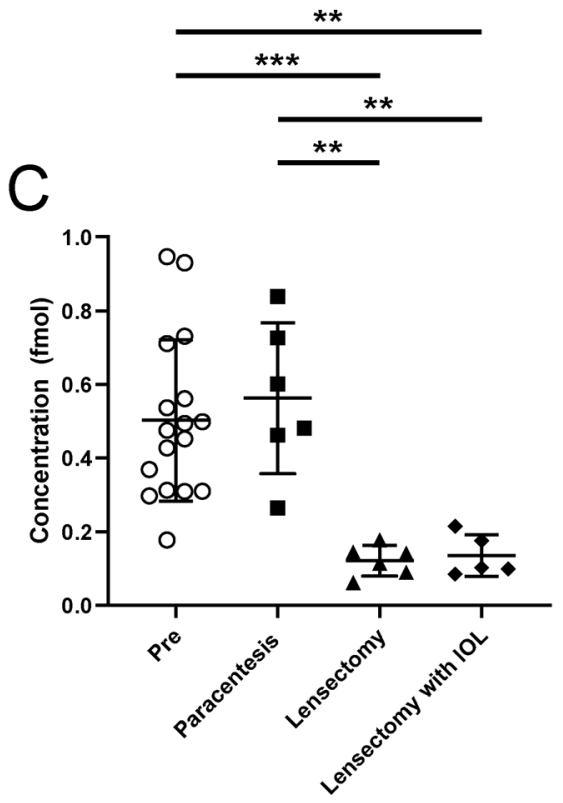

Fig. 5 Relative concentrations of (A) FGB, (B) TGF- $\beta 2$ and (C) RBP3. Graphs show measurements of endogenous proteins determined by PRM relative to SIL peptides, with each symbol representing one rabbit within a surgical group.

discovery approach (Fig. 5A). Of note, there was no significant difference in FGB between the lensectomy with and without IOL insertion, despite the drastic increase of the fibrin scar. A more in-depth quantitative analysis of the $\mathrm{AH}$ proteome may reveal potential explanations for the clinical observation that IOL insertion exacerbates the fibrin scar more than with lensectomy alone.

Conversely, a number of proteins were observed to decrease in abundance with each surgical step (Fig. 4, 5B, C, Table 2 and Table S7, ESI $\dagger$ ). The eye is an immune privileged site that constitutively expresses both immunoregulatory and immunosuppressive proteins. ${ }^{19,20}$ Immune privilege is maintained by multiple components including immunosuppressive proteins such as TGF- $\beta 2 .{ }^{21-23}$ Unlike adults, juveniles may lack a developed ocular immune inhibition cascade and ocular immune privilege, thus allowing for an exaggerated postoperative response. This lack of immune inhibition may also play a role in autoimmune diseases of the eye. A previous study found low levels of TGF- $\beta 2$ in cases of uveitis, a condition of ocular inflammation. ${ }^{24}$ Therefore, TGF- $\beta 2$ may be associated with constitutive ocular immunosuppression, and thus a decrease in the abundance of this protein would allow exaggerated inflammation and scarring to occur. Consistent with this general principle, our analyses of AH reveal that TGF- $\beta 2$ and latent TGF- $\beta 2$ significantly decreased in abundance following any surgical intervention (Table 2). The use of SIL peptides to confirm this decrease lends further strength to this observation, especially following lensectomy and lensectomy with IOL (Fig. 5B). These data support the point that proper maintenance of TGF- $\beta 2$ levels in the aqueous humor may be an approach for actively maintaining suppression of the immune response following intraocular surgery.
In addition, there was also a decrease in relative abundance of RBP3 with each progressive surgical intervention. While RBP3 has been previously reported in the $\mathrm{AH},{ }^{25,26}$ the role of RBP3 in the anterior chamber (AC) is not yet known. Bouhenni and colleagues observed decreased abundance of RBP3 in preoperative $\mathrm{AH}$ samples of children with pediatric congenital glaucoma. As RBP3 is a retinoid transporter, Bouhenni et al. suggests decreased RBP3 may result in few retinoids in the AC, noting that retinoids play a role in tissue development of the anterior segment. ${ }^{25}$ Our work reveals that RBP3 decreases in abundance at each surgical step, where a worse clinical outcome is observed at each stage (Table 2 and Fig. 5C). This observation regarding RBP3 in the anterior chamber is consistent with a previous study that demonstrated that RBP3 levels were decreased or undetectable with increased uveitic disease activity, a form of inflammation in the middle layer of tissue in the eye wall. ${ }^{27}$ Further research is needed to properly determine the role of RBP3 in the AC to decipher if loss of RBP3 (1) prevents immunosuppressive activity involved in the response to intraocular surgery, or (2) alters tissue recovery or development.

It is noted that while two SIL peptides for TGF- $\beta 2$ and FGB had CV values less than $15 \%$, only one peptide for RBP3 met this criterion for peptide stability. Despite this limitation, the quantitative trends observed for the targeted quantitation are consistent with the discovery data for which multiple peptides were included. Also, although statistical significance was achieved for targeted quantitation applied to a subset of the cohort, future targeted studies will be required to fully validate these observations across a larger cohort of samples. Finally, it is possible that outliers in the paracentesis PCA grouping (Fig. 3A) may have resulted from an inadvertent violation of 
the lens capsule during sampling; however, this was not observed by the surgeon during the sample collection. Rabbits with a large PC1 component did demonstrate a high abundance of crystallin proteins, supporting this possibility. For the two paracentesis eyes in which the lenses were known to be touched during sample acquisition, this does account for the higher fibrin scar coverage as shown in Fig. 2F.

\section{Conclusions}

Overall, these analyses of AH proteins that are differentially abundant in response to surgical step-wise interventions reveal specific proteins involved in coagulation and immunosuppression, which are possibly involved in the underlying causes of inflammation and scarring after juvenile intraocular surgery. Going forward, it is expected that these results from an animal model will inform future translational studies. Although human proteomic $\mathrm{AH}$ analyses have been performed, ${ }^{25,28-41}$ few have applied this work to pediatric subjects. Therefore, data from the current study will support efforts that compare the AH proteins identified in juvenile rabbits to those found in infants in future work. In addition, these data provide a baseline for comparisons to an aging rabbit model and those in adult humans, which are expected to reveal insights to explain why adults have a minimal ocular immune response following cataract surgery, unlike children. As rabbits age, similar to human adults, the observed postoperative inflammatory response becomes less severe. ${ }^{8}$ Therefore, it is expected that future studies aimed at determining which proteins differ in abundance either prior to or after surgical intervention with aging may reveal the mechanism for the exaggerated immune response observed following cataract surgery with IOL insertion in infants. This work provides foundational proteomics data in a rabbit animal model highly suitable for translational pediatric ocular research.

\section{Abbreviations}

$\begin{array}{ll}\text { AH } & \text { Aqueous humor } \\ \text { AALS-I } & \text { Anionic acid labile surfactant I } \\ \text { ANOVA } & \text { Analysis of variance } \\ \text { BCA } & \text { Bicinchoninic acid } \\ \text { CV } & \text { Coefficient of variation } \\ \text { DDA } & \text { Data dependent acquisition } \\ \text { DIA } & \text { Data independent acquisition } \\ \text { FGB } & \text { Fibrinogen-beta chain } \\ \text { IOL } & \text { Intraocular lens } \\ \text { LC-MS/MS } & \text { Liquid chromatography tandem mass } \\ & \text { spectrometry } \\ \text { MS } & \text { Mass spectrometry } \\ \text { PCA } & \text { Principal component analysis } \\ \text { POD3 } & \text { Post-operative day 3 } \\ \text { PRM } & \text { Parallel reaction monitoring } \\ \text { PRTC } & \text { Peptide retention time calibration } \\ \text { RBP3 } & \text { Retinol binding protein 3 } \\ \text { RPM } & \text { Revolutions per minute }\end{array}$

SIL Stable isotopically labeled

TCEP Tris(2-carboxyethyl)phosphine

TGF- $\beta 2$ Transforming growth factor beta-2.

\section{Conflicts of interest}

There are no conflicts to declare.

\section{Acknowledgements}

This work was supported by the NIH [K08EY024645 (ISK), P30EY001931; F31-HL140914 (MW); R01HL126785 and R01HL134010 (RLG)] and the Center for Biomedical Mass Spectrometry Research at the Medical College of Wisconsin. The content is solely the responsibility of the authors and does not necessarily represent the official views of the National Institutes of Health. The authors would also like to thank Michael Pereckas for assistance with MS studies. All MS analyses were performed in the Center for Biomedical Mass Spectrometry Research.

\section{References}

1 C. Gilbert and A. Foster, Bull. W. H. O., 2001, 79, 227-232.

2 S. Sheeladevi, J. G. Lawrenson, A. R. Fielder and C. M. Suttle, Eye, 2016, 30, 1160-1169.

3 L. M. Hamm, J. Black, S. Dai and B. Thompson, Front. Psychol., 2014, 5, 583.

4 M. C. Ventura, B. V. Ventura, C. V. Ventura, L. O. Ventura, T. E. Arantes and W. Nose, J. Cataract Refractive Surg., 2014, 40, 601-608.

5 D. A. Plager, M. J. Lynn, E. G. Buckley, M. E. Wilson and S. R. Lambert, Infant Aphakia Treatment Study Group, Am. J. Ophthalmol., 2014, 158, 892-898.

6 A. Gremida, I. Kassem and A. Traish, Digital J. Ophthalmol., 2011, 17, 66-68.

7 J. D. Bogaard, J. B. Young, A. Movahedan and I. S. Kassem, Transl. Vis. Sci. Technol., 2019, 8, 5.

8 A. Gwon, in Animal Models in Eye Research, ed. P. Tsonis, Elsevier, 2008, ch. 13, pp. 184-204.

9 M. Stastna, A. Behrens, G. Noguera, S. Herretes, P. McDonnell and J. E. Van Eyk, Proteomics, 2007, 7, 4358-4375.

10 M. Stastna, A. Behrens, P. J. McDonnell and J. E. Van Eyk, Proteome Sci., 2011, 9, 8.

11 M. Bern, G. Finney, M. R. Hoopmann, G. Merrihew, M. J. Toth and M. J. MacCoss, Anal. Chem., 2010, 82, 833-841.

12 G. Dennis, Jr., B. T. Sherman, D. A. Hosack, J. Yang, W. Gao, H. C. Lane and R. A. Lempicki, Genome Biol., 2003, 4, P3.

13 B. MacLean, D. M. Tomazela, N. Shulman, M. Chambers, G. L. Finney, B. Frewen, R. Kern, D. L. Tabb, D. C. Liebler and M. J. MacCoss, Bioinformatics, 2010, 26, 966-968.

14 S. A. Carr, S. E. Abbatiello, B. L. Ackermann, C. Borchers, B. Domon, E. W. Deutsch, R. P. Grant, A. N. Hoofnagle, R. Huttenhain, J. M. Koomen, D. C. Liebler, T. Liu, B. MacLean, D. R. Mani, E. Mansfield, H. Neubert, 
A. G. Paulovich, L. Reiter, O. Vitek, R. Aebersold, L. Anderson, R. Bethem, J. Blonder, E. Boja, J. Botelho, M. Boyne, R. A. Bradshaw, A. L. Burlingame, D. Chan, H. Keshishian, E. Kuhn, C. Kinsinger, J. S. Lee, S. W. Lee, R. Moritz, J. OsesPrieto, N. Rifai, J. Ritchie, H. Rodriguez, P. R. Srinivas, R. R. Townsend, J. Van Eyk, G. Whiteley, A. Wiita and S. Weintraub, Mol. Cell. Proteomics, 2014, 13, 907-917.

15 M. Choi, C. Y. Chang, T. Clough, D. Broudy, T. Kileen, B. MacLean and O. Vitek, Bioinformatics, 2014, 30, 2524-2526. 16 M. W. Mosesson, J. Thromb. Haemostasis, 2005, 3, 1894-1904. 17 A. Ayala, D. J. Warejcka, M. Olague-Marchan and S. S. Twining, Invest. Ophthalmol. Visual Sci., 2007, 48, 134-143.

18 T. F. Dyrlund, E. T. Poulsen, C. Scavenius, C. L. Nikolajsen, I. B. Thogersen, H. Vorum and J. J. Enghild, J. Proteome Res., 2012, 11, 4231-4239.

19 A. W. Taylor, Eye, 2009, 23, 1885-1889.

20 J. W. Streilein, J. Leukocyte Biol., 2003, 74, 179-185.

21 R. Shechter, A. London and M. Schwartz, Nat. Rev. Immunol., 2013, 13, 206-218.

22 M. Coca-Prados, J. Glaucoma, 2014, 23, S36-S38.

23 R. Zhou and R. R. Caspi, F1000 Biol. Rep., 2010, $2,3$.

24 J. H. de Boer, J. Limpens, S. Orengo-Nania, P. T. de Jong, E. La Heij and A. Kijlstra, Invest. Ophthalmol. Visual Sci., 1994, 35, 3702-3710.

25 R. A. Bouhenni, S. Al Shahwan, J. Morales, B. T. Wakim, A. M. Chomyk, F. S. Alkuraya and D. P. Edward, Exp. Eye Res., 2011, 92, 67-75.

26 U. R. Chowdhury, B. J. Madden, M. C. Charlesworth and M. P. Fautsch, Invest. Ophthalmol. Visual Sci., 2010, 51, 4921-4931.

27 F. J. Descamps, D. Kangave, B. Cauwe, E. Martens, K. Geboes, A. Abu El-Asrar and G. Opdenakker, J. Cell. Mol. Med., 2008, 12, 2449-2456.

28 K. L. Bennett, M. Funk, M. Tschernutter, F. P. Breitwieser, M. Planyavsky, C. Ubaida Mohien, A. Muller, Z. Trajanoski,
J. Colinge, G. Superti-Furga and U. Schmidt-Erfurth, J. Proteomics, 2011, 74, 151-166.

29 X. Duan, Q. Lu, P. Xue, H. Zhang, Z. Dong, F. Yang and N. Wang, Mol. Vision, 2008, 14, 370-377.

30 D. P. Edward and R. Bouhenni, Trans. Am. Ophthalmol. Soc., 2011, 109, 66-114.

31 M. Funding, H. Vorum, B. Honore, E. Nexo and N. Ehlers, Acta Ophthalmol. Scand., 2005, 83, 31-39.

32 F. H. Grus, S. C. Joachim, S. Sandmann, U. Thiel, K. Bruns, K. J. Lackner and N. Pfeiffer, Mol. Vision, 2008, 14, 1437-1445.

33 Y. Ji, X. Rong, H. Ye, K. Zhang and Y. Lu, Clin. Biochem., 2015, 48, 1304-1309.

34 M. A. Kaeslin, H. E. Killer, C. A. Fuhrer, N. Zeleny, A. R. Huber and A. Neutzner, PLoS One, 2016, 11, e0165314.

35 T. W. Kim, J. W. Kang, J. Ahn, E. K. Lee, K. C. Cho, B. N. Han, N. Y. Hong, J. Park and K. P. Kim, J. Proteome Res., 2012, 11, 4034-4043.

36 A. A. Kliuchnikova, N. I. Samokhina, I. Y. Ilina, D. S. Karpov, M. A. Pyatnitskiy, K. G. Kuznetsova, I. Y. Toropygin, S. A. Kochergin, I. B. Alekseev, V. G. Zgoda, A. I. Archakov and S. A. Moshkovskii, Proteomics, 2016, 16, 1938-1946.

37 N. Perumal, C. Manicam, M. Steinicke, S. Funke, N. Pfeiffer and F. H. Grus, PLoS One, 2017, 12, e0172481.

38 M. R. Richardson, M. O. Price, F. W. Price, J. C. Pardo, J. C. Grandin, J. You, M. Wang and M. C. Yoder, Mol. Vision, 2009, 15, 2740-2750.

39 J. Soria, A. Villarrubia, J. Merayo-Lloves, F. Elortza, M. Azkargorta, J. Alvarez de Toledo, I. Rodriguez-Agirretxe, T. Suarez and A. Acera, Mol. Vision, 2015, 21, 451-460.

40 Q. Yang, H. Lu, X. Song, S. Li and W. Wei, PLoS One, 2016, 11, e0158611.

41 J. Yao, Z. Chen, Q. Yang, X. Liu, X. Chen, M. Zhuang and Q. Liu, Int. J. Mol. Med., 2013, 32, 1421-1434. 